\title{
Naming, Reference, and Sense: Theoretical and Practical Attitudes at Odds
}

\author{
ANDREW NORMAN \\ Northwestern University
}

Three questions lie at the center of the philosophical controversy over proper names:

1) Do proper names have a sense?

2) If so, does the sense fix the reference?

3) Are name-to-name identity claims about words or their referent(s)?

These questions have given rise to considerable dispute. The reason for this, I will argue, is that each is crucially ambiguous. The issues hinge on the interpretation given to 'have', 'fix' and 'about', respectively. Recognizing these ambiguities makes it possible to give the disputants on each side their due. It also removes some of the puzzlement that occasions these questions. I will conclude that proper names do not possess a sense, but carry one; that sense can help fix reference initially, but need not thereafter; and that name-to-name identity claims can convey information about words even though they do not describe them.

1. The problem with answering the first question in the negative is that one then has trouble explaining how name-to-name identity claims (such as "Hesperous is Phosphorous") can have real cognitive and empirical content. Frege argued that if names have only reference and no sense, then identity claims that equate them should be analytic, and devoid of cognitive content. But they aren't analytic; they often have cognitive, even empirical content. So names must have sense ([1], pp. $25 \mathrm{ff}$ ).

If one answers the first question in the affirmative, however, it would seem that one must then give an account of what this sense consists in. One such account is typically associated with Russell. According to Russell, a name is just a shorthand for a description, the description giving the sense of the name ([3], p. 62). The problem with this view is that a statement predicating of the named thing a feature mentioned in its "defining" description would then be analytic. For example, if being the highest mountain in the world is Everest's defining feature, then the claim 
that Everest is that would be an analytic truth.1 But that is a contingent and empirical fact. Hence a name cannot be just a shorthand for a description.

Another account of the sense of a name identifies it with that of a cluster of descriptions. But this does not remove the difficulty. For it makes no difference whether the predicate "is the highest mountain in the world" identifies the lone identifying property of Everest, or just one amongst many. As long as such descriptions are spoken of as belonging to the name itself, or making up its sense, then (on the supposition that meaning includes sense,) the claim: "Everest is the highest mountain in the world" will remain true by virtue of the meaning of the terms alone, and thus count as analytic.

A significant step towards the resolution of this puzzle was made, I think, when Searle identified an ambiguity in the question:

If this ["Do proper names have a sense?"] asks whether or not proper names are used to describe or specify characteristics of objects, the answer is 'no'. But if it asks whether or not proper names are logically connected with characteristics of the object to which they refer, the answer is 'yes, in a loose sort of way' ([4], p. 96).

I think that Searle has diagnosed the core of the problem. But I also think that the distinction he makes needs to be spelled out more fully if we are to avoid confusion. The "have" of our question is ambiguous. It can be understood as indicating anything from a very strict to a much "looser" connection. (I am not quite sure what it means here to call this connection "logical.") On a suitably strong reading, the question is whether names possess a sense, or whether an internal relation obtains between a name and certain descriptions of the object it designates. It asks, that is, whether such descriptions belong to the (meaning of the) name. Such a construal would clearly incline one towards a negative answer, for a positive answer has the unpleasant consequence that the attribution to a name of properties contained in its sense would be (but ought not to be,) analytic.

On a more forgiving reading of "have," a name need only be contingently related-indeed merely associated-with a description. That is, a name has a sense if it connotes. This reading makes it difficult to deny that names have sense. To avoid confusion, let us say that a name can carry a sense, even if it does not possess one. The distinction allows us to

1 Of course, being the highest mountain in the world is a relational, and presumably contingent, property. One might, a la Kripke, use a predicate that employs a pronoun (like the property of having its unique history), to construct an example with a somewhat different force. We will examine Kripke's conception of rigid designation in what follows. 
present a thesis that avoids the difficulties the stronger claim founders on, yet still allows us to explain the fact that we can learn from name-to-name identity claims. In brief, a name can carry a sense, though it need not possess one. The question of whether names do in fact possess sense, of course, remains. ${ }^{2}$

2 The fact that descriptions are useful and often necessary for the purposes of learning to use a name lends credence to the view that sense determines reference. For without a description to pick out the thing to be named, how is the learner to identify that which the name names? In cases where the learner is not acquainted with the object, it would seem that description, or invocation of sense, is indispensible. Even in cases of ostension, description is often necessary to mitigate indeterminacy. The question, as Searle puts it, is this: "As a proper name does not in general specify any characteristics of the object referred to, how then does it bring the reference off?" ([4], p.94).

The idea that a single characteristic picks out a name's reference runs into difficulty over the fact that we can usually without contradiction imagine discovering that the object in question did not have the supposedly definitive characteristic. We might, for instance, discover that Everest is not really the tallest mountain in the world. To deal with this problem, Searle gives what Kripke calls the "cluster theory" of naming. It amounts to the idea that a certain indeterminate class of descriptions together pick out the object: that a sense composed of a complex of descriptions determines reference.

This account has the virtue of explaining how the reference of 'Aristotle' can remain fairly stable through changes in what we know about Aristotle. Because the reference of 'Aristotle' is not fixed by one description alone, but by a set of overlapping descriptions, we are not

2 This question should be seen in connection with that of whether the use of a name involves asserting or presupposing the name's sense. Where Russell affirmed that a claim employing a name does assert that the name's referent has the properties indicated by its sense, Frege denied this. I think that Grice's studies of conversational implicature offer interesting possibilities for giving an account of this relation. Thus: The present king of France is bald' might conversationally imply that there is a present king of France, even though it does not entail or assert that there is a present king of France. Whether or not it presupposes this will depend on how one understands "presupposition." For example, if one gives the following, justification-conditions account of presupposition: $P$ presupposes $R$ iff showing that $R$ is false undermines the force of $P$, then one would have to count "There is a present king of France" as a presupposition of "The present king of France is bald." Although these are interesting questions, they cannot be pursued in depth here. 
thrown into immediate perplexity when it is suggested that Aristotle might not, after all, have, say, written the Nichomachean Ethics.

Searle argues that his account has the correlative virtue that it explains the real indeterminacy in our criteria of individuation. Suppose we discovered that Aristotle did not write the Nichomachean Ethics or study with Plato. Would he still be Aristotle? How much of what we now attribute to Aristotle would have to be discovered to belong to another man before 'Aristotle' would refer to him instead? We should expect indeterminacy just here because the question of what Aristotle's defining features are is "not decided for us in advance" ([4]. p. 94). Reference, on this account, seems to be determined somewhat indefinitely by a cluster of descriptions.

Kripke says of this "cluster" account that it "really is a nice theory. The only defect I think it has is probably common to all philosophical theories. It's wrong" ([2], p. 64). He begins his critique by attacking Searle's claim that "it is a necessary fact that Aristotle has the logical sum, inclusive disjunction, of properties commonly attributed to him: any individual not having at least some of these properties could not be Aristotle" ([4], p. 95). Kripke flat out denies that this is necessary, claiming that "it's a contingent fact that Aristotle ever did any of the things commonly attributed to him today, any of the great achievements we so much admire" ([2], p. 75).

His basis for this judgement is his claim that proper names designate rigidly, or refer to their objects across all possible worlds. We can vary, in imagination, Aristotle's (contingent) characteristics, accomplishments, and properties quite freely, and still 'Aristotle' would refer to Aristotle. It is a condition on the possibility of imagining a different Aristotle that 'Aristotle' rigidly designate just him. He might have died as a child, for instance, and still Aristotle would have been. That he wrote the Ethics, studied with Plato, and taught Alexander the Great are all contingent truths-they might have been otherwise. But that he would not have been Aristotle is inconceivable.

The upshot of this asymmetry between names and descriptions is that sense does not determine reference. For although the set of descriptions that make up the sense of a name seldom picks out a unique object, probably not uncommonly picks out the wrong object, and sometimes fails to pick out an object at all, the name that carries it still refers. ${ }^{3}$ That is, though all of these ways of "determining" reference might fail, the name would still refer to its object. What makes it possible for a name to do this? For Kripke, simply the fact that it designates rigidly. All of which means that reference is fixed by something other than sense.

Kripke's alternative account of how reference is fixed is causal. Beginning with an ostensive or descriptive "initial baptism," a name is "passed from link to link" along a causal chain, each receiver of the name

3 This, I take it, is the jist of Kripke's argument. See pp. 80-90. 
intending to use it to designate the same referent as the user before ([2], p.96). Clearly Kripke has radically reconceived what it is to fix a reference. And on the basis of this reconception, he denies that sense is what fixes reference.

So who is right, Searle or Kripke? It seems to me that the issue turns on what the question: "What fixes reference?" is asking for. The question is ambiguous. Does it ask for an account of some mysterious and ineffable connection called "picking out" by virtue of which the use of a name is able to refer? The notion of rigid designation might seem to call for an account of this kind, but Kripke's causal model of reference-fixing constitutes a strong implicit denial that we ought to think in such terms. His construal of what it is to "fix" reference is concrete and historical. Thus demystifying the question, however, does not remove the ambiguity. Does it ask for a genetic account--that is, a story about the origin of the name-where fixing is understood in causal-historical terms? Or does it request, rather, some psychological story about how reference is initially and thereafter anchored in any given agent's linguistic competence? The question itself, I think, does not tell us.

Initial baptisms often require descriptions to individuate the object to be named. Does this mean that, in such cases, sense determines reference? If we look at the bare fact that a description is helping the potential user of a name identify its object, it can look that way. But how can the description be thought of as part of the name's sense, when the naming relation has not yet been set up? And how about each new link in the chain? Doesn't the reference need to be fixed for each new user? How else could new users come to learn the correct use of the name? And don't descriptions function generously in this fixing, often constituting all the potential user has to go on in figuring out to what the name refers? Doesn't this mean that sense determines reference?

It seems relatively clear that descriptions play an important role in the learning (certainly one sense of "fixing") of names. Searle's account is a reminder of this dimension of reference-fixing. Kripke's denial that sense determines reference is intended to point at something else: the fact that a learned name in some sense frees itself from the descriptions that initially anchored it. While I may have learned the name 'Moses' by means of the description: 'the man that parted the Red Sea,' I may subsequently come to question whether in fact Moses did accomplish this feat. The only reason that such speculation is not simply self-contradictory or incoherent is that the name 'Moses' has freed itself from the description that initially anchored it in my understanding. The contingency of such claims as 'Moses parted the Red Sea' is definitive evidence, for Kripke, that it is not sense that fixes reference. The reference of 'Moses' is rather fixed by a causal chain of a particular kind that leads back to Moses himself.

So in what sense, if any, can we say that sense determines reference? An adequate answer, I think, should take account of the following. In the 
context of an 'initial baptism', description often plays a part in fixing reference, by helping the baptizers to pick out what is to be christened with the new name. Sense can play a similar role each time the use of a name is taught to a new user. But once someone's conception of a named thing is sufficiently rich and stable, it frees itself from dependence upon contingent descriptions, and can designate rigidly. 4 The reference thereafter remains fixed upon its object, no longer determined by its sense. So to "fix reference" can mean any of several things, among them to 'baptize', 'pick out', 'help get a handle on', 'anchor' and 'designate rigidly'. Although precision would perhaps best be served by unasking the question entirely, we can indicate a rough resolution to the Kripke-Searle debate with the phrase: sense may help determine reference initially, but it need not thereafter. 5

3. And these same philosophers have taken different sides on the issue of what name-to-name identity claims are about as well. Frege argues that, on the view that such claims express a "relation between objects," such a claim is reduced to an analytic expression of self-identity. But how, then, can one explain the fact that identity claims sometimes constitute valuable extensions of our knowledge?

A relation would thereby be expressed of a thing to itself, and indeed one in whch each thing stands to itself but to no other thing. What we apparently want to state by $a=b$ is that the signs or names ' $a$ ' and ' $b$ ' designate the same thing, so that those signs themselves would be under discussion ([1], p. 56).

What a sentence like "Cicero is Tully" tells us is that these two different names designate the same thing; that we can use the names interchangeably. The statement is about, and expresses an identity

\footnotetext{
4 Two comments on this are perhaps in order. First, I cannot say precisely what I mean by a "sufficiently rich and stable" conception. I do not know whether, for example, such a conception involves a cluster of descriptions. It would, I think, involve a certain degree of competence in the use of the name, and a measure of confidence in one's ability to use it competently. Second, my aim here is not to assert the priority of descriptions in the fixing of reference. The comment simply expresses a phenomenological observation.

5 Searle actually considers this 'solution' to the dilemma, but ties it upunnecessarily, I think- with the thesis that names do not have (or carry) a sense at all. He then rejects it on the basis of this quite spurious association. See pp. 91-92.
} 
between, names, even though it is made true by the fact that their referents are identical.

Searle takes the opposite view. "The statement (Cicero $=$ Tully)," he says, "is not about words." His argument consists first in distinguishing illustration from description. Such a claim, he argues, "illustrates or exemplifies certain contingent facts about words, though it does not of course describe these facts." Though it might show us something about names, it does not follow that it describes or is about those names. "People who argue that Shakespeare was Bacon," he points out, "are not advancing a thesis about language" ([4], pp. 89-90).

Searle admits, however, that a name-to-name identity claim "could be used to make an analytic statement" (i.e. about words), but that "it does not follow that it could not also be used to make a synthetic statement" (i.e. about objects in the world) ([4], p. 90). So for Searle, it seems that such claims are themselves "not about words", but they can be used to tell us about words or things. To avoid a contradiction, it seems Searle must make a distinction between what an identity claim tells us (under certain circumstances, and with reference to certain purposes), and what the claim is (really) about. I'm not sure that such a distinction can be maintained, but 1 do think that its origin and rationale can be explained.

Searle's advice that we look at the context and the use is instructive. Imagine a situation in which a name-to-name identity claim might arise and serve a definite purpose. I am telling a story, and my listener has not yet figured out that two names I have been using refer to the same character. I mention that Dr. Jekyll has a certain characteristic--for example, that he is an exceptionally furry fellow- and my friend responds with perplexity: "I thought it was Mr. Hyde that was the exceptionally furry fellow-?" "Don't you get it?," I say, "Dr. Jekyll is Mr. Hyde."6

Now was my last statement about names or their (common) referent? The simple self-identity of Dr. Jekyll and Mr. Hyde is not what motivates me to make the identity claim. The claim only has significance, (i.e. a role) because my friend has not yet linked the two names and the sets of descriptions that attach to each. I am aware of this, and my speech act is a conscious attempt to help her link the two sets of descriptions. Searle's claim that "names function as pegs on which we hang descriptions" is useful here ([4], p. 95). For it seems that what I convey to her is that each name-peg will bear the weight of the other's descriptions. ("Oh, I see!," she might say, "Now I can go on!") Viewed with an eye towards its practical significance, the statement appears to be about words as much as about their referents.

But from a more theoretical vantage-point, it seems necessary to distinguish what the statement refers to directly from what it makes reference to indirectly. And what it speaks of directly is not words, but Dr.

6 Thanks to Todd Grantham for this exceptionally nice example. 
Jekyll and Mr. Hyde, the character(s). From this perspective, what the claim is really about is Dr. Jekyll/Mr. Hyde. Strictly (or theoretically) speaking, the statement is not about words.

This controversy is generated, apparently, by the fact that we can look at and understand a name-to-name identity claim in two radically different ways. We can see it in context, as a practically-oriented speech act; and we can equally well see it in isolation, from a theoretical vantagepoint, as a statement that is about the thing(s) to which the names refer. The question of whether name-to-name identity claims are about words or their objects is the question of which attitude it is appropriate to adopt. But the question is unsituated: it does not give us enough information to determine which attitude is appropriate. It seems to me that either attitude might be correct; that neither has exclusive rights here. Although neither claim is incorrect, neither gets at the whole truth.

It now becomes possible to re-interpret the first two controversies in light of the insights generated by the last. They, too, represent showdowns between the theoretical and the practical attitude. The view that names do not have a sense is the result of viewing them from the theoretical vantagepoint, which wants to distinguish what belongs to the name in itself, from what is attached to it only contingently. The opposing view, that names do have sense, is the way the practical attitude sees the matter: what names are is what they do, and neither can be isolated from their sense. The conclusion we teached before, that names carry but do not possess sense, can now be seen as an attempt to adjudicate between the theoretical and the practical attitudes. It was based, however, on a distinction between what properly ('internally', 'necessarily', 'really') belongs to a name, and what just attaches to it ('externally', 'contingently', etc.).7 Does this not constitute a capitulation to the demands of the theoretical attitude? Perhaps. But due to the fact that there are no obvious or immediate alternatives, this resolution itself constitutes a rough and ready practical solution to the dilemma at hand. It may not put the issue to rest, but it does, I think, give us a more perspicuous view of the problem.8

71 do not think that this must be conceived as a distinction with theoretical integrity for this resolution to work. The difference it indicates, that is, may be a matter of degree rather than of kind. Thus viewed, I think, one needn't take issue with Quine's denial of the analytic/synthetic distinction. (Quine's argument against that distinction presupposes that a distinction must have theoretical integrity to be a distinction at all.)

8 There is, no doubt, more work to be done here. My thanks to Keith Coleman for pointing this out, and for exceptionally helpful comments all around. 
Clearly also the thesis that sense determines reference is an outgrowth of the practical attitude, and its denial a product of the theoretical attitude. If you attend to context, and are concerned about the practical problem of how names are learned, you are likely to support the idea that sense fixes reference. If, on the other hand, you attend to the fact that names fix rigidly upon their referents, despite changes in characteristics and knowledge-even through counterfactual variation of the thing in question-you are positing, from the theoretical standpoint, a context-invariant reference relation. Which attitude and corresponding thesis is correct? Neither and both. The ambiguity of the phrase "fixes the reference" allows the question to be interpreted differently from the theoretical and the practical standpoints. The resolution offered previously-that sense fixes reference initially, but not thereafter--is likewise revealed to be a pragmatic attempt to adjudicate between what might in the end be fundamentally irreconcilable attitudes.

\section{References}

[1] Gottlob Frege. "On Sense and Reference", Zeitschrift vol. 100 (1892).

[2] Saul Kripke. Naming and Necessity. Cambridge, MA: Harvard University Press 1972.

[3] Bertrand Russell. Philosophy of Logical Atomism. LaSalle, Il: Open Court Press, 1985.

[4] John Searle. "Proper Names," in P.F. Strawson ed. Philosophical Logic. Oxford: Oxford University Press, 1967. 